\title{
Corrigendum: Patients with schizophrenia fail to up-regulate task-positive and down-regulate task-negative brain networks: an fMRI study using an ICA analysis approach
}

\section{Merethe Nygård ${ }^{1}$, Tom Eichele ${ }^{1,2,3,4}$, Else-Marie Løberg ${ }^{1,5}$, Hugo A. Jørgensen ${ }^{6}$, Erik Johnsen $^{5,6}$, Rune A. Kroken ${ }^{5}$, Jan Ø. Berle ${ }^{6}$ and Kenneth Hugdahl ${ }^{1,5,7 *}$}

${ }^{1}$ Department of Biological and Medical Psychology, University of Bergen, Bergen, Norway

2 Section for Clinical Neurophysiology, Haukeland University Hospital, Bergen, Norway

${ }^{3}$ Department of Biomedicine, K.G. Jebsen Centre for Research on Neuropsychiatric Disorders, University of Bergen, Bergen, Norway

${ }^{4}$ Mind Research Network, Albuquerque, NM, USA

${ }^{5}$ Division of Psychiatry, Haukeland University Hospital, Bergen, Norway

${ }^{6}$ Section of Psychiatry, Department of Clinical Medicine, University of Bergen, Bergen, Norway

7 Department of Radiology, Haukeland University Hospital, Bergen, Norway

*Correspondence: hugdahl@psybp.uib.no

Edited by:

John J. Foxe, Albert Einstein College of Medicine, USA

A commentary on

Patients with schizophrenia fail to up-regulate task-positive and downregulate task-negative brain networks: an fMRI study using an ICA analysis approach

by Nygård, M., Eichele, T., Løberg, E-M., Jørgensen, H. A., Johnsen, E., Kroken, R. A., et al. (2012). Front. Hum. Neurosci. 6:149. doi: 10.3389/fnhum. 2012.00149

p. 4, "MR IMAGING" section, line 20 from bottom:
The following sentences

"[...] The T1-images were acquired with an EPI sequence. The T1-images were acquired with a FSPGR pulse sequence with 122 sagittal slices $[64 \times 64$ matrix size, slice thickness $=1.0 \mathrm{~mm}$, echo time $(\mathrm{TE})=30 \mathrm{~ms}$, repetition time $(\mathrm{TR})=$ $1.5 \mathrm{~s}$, flip angle $(\mathrm{FA})=90]$. [...]"

should be replaced by

"[...] The T1-images were acquired with a FSPGR pulse sequence with 180 sagittal slices $[256 \times 256$ matrix size, field of view $(\mathrm{FoV})=256 \times 256 \mathrm{~mm}^{2}$, slice thickness $=1.0 \mathrm{~mm}$, inversion time $(\mathrm{TI})=$ $500 \mathrm{~ms}$, flip angle $(\mathrm{FA})=11] .[\ldots]^{\prime \prime}$
Received: 13 May 2013; accepted: 14 May 2013; published online: 30 May 2013.

Citation: Nygård $M$, Eichele T, Løberg E-M, Jørgensen HA, Johnsen E, Kroken RA, Berle JO and Hugdahl K (2013) Corrigendum: Patients with schizophrenia fail to up-regulate task-positive and down-regulate task-negative brain networks: an fMRI study using an ICA analysis approach. Front. Hum. Neurosci. 7:231. doi: 10.3389/fnhum. 2013.00231

Copyright (C) 2013 Nygård, Eichele, Løberg, Jørgensen, Johnsen, Kroken, Berle and Hugdahl. This is an open-access article distributed under the terms of the Creative Commons Attribution License, which permits use, distribution and reproduction in other forums, provided the original authors and source are credited and subject to any copyright notices concerning any third-party graphics etc. 